\title{
Entrepreneurial Intentions and Behaviour as the Creation of Business: Based on the Theory of Planned Behaviour Extension Evidence from Polish Universities and Entrepreneurs
}

Intenciones empresariales y comportamiento como la creación de negocios: basado en la teoría de la evidencia de extensión de comportamiento planificado de universidades y empresarios polacos

\author{
Mohammad Heydari \\ Nanjing University of Science and Technology, Nanjing, Jiangsu, China \\ ORCID: https://orcid.org/0000-0003-3942-2107 \\ Zhou Xiaohu \\ Nanjing University of Science and Technology, Nanjing, Jiangsu, China \\ ORCID: https://orcid.org/0000-0002-9634-5403 \\ Kin Keung Lai \\ Shenzhen University, Shenzhen, China \\ ORCID: https://orcid.org/0000-0002-9417-6706 \\ Yufan Shang \\ Xi'an Jiaotong University, Xi'an, Shaanxi, China. \\ ORCID: https://orcid.org/0000-0001-6407-711X
}

Received 02-12-20 Revised 03-13-20 Accepted 07-13-20 On line 08-29-20

*Correspondence

Email: njustzxh@njust.edu.cn
Cite as:

Heydari, M., Xiaohu, Z., Lai, K. K., \& Shang, Y. (2020). Entrepreneurial Intentions and Behaviour as the Creation of Business: Based on the Theory of Planned Behaviour Extension Evidence from Polish Universities and Entrepreneurs. Propósitos y Representaciones, 8 (SPE2), e674 Doi: http://dx.doi.org/10.20511/pyr2020.v8nSPE2.674 


\section{Summary}

The purpose of this research was to analyze the relationships between the factors that influence entrepreneurial Intention (EI), using a modified version of Ajzen's theory of planned behaviour (TPB), considering the perception of behaviour. This examination depended on participants' demographic characteristics and psycho-social behavioural traits of attitude (ATT), Subjective norm (SN), and perceived behavioural control (PBC). The establishment of a new business entails various forms of action to achieve desired results. This research analyzes entrepreneurship as the creation of business by engaging in rational behaviour to optimize the use of available technologies and financial sources. These activities are not standardized: They emerge from the entrepreneurial imagination, the perception of new opportunities, and innovation. The aim of a business is not just to produce and sell goods or services. A company must determine the appropriate means of providing them and choose the values to be adopted in the procedure of doing so. Companies should also identify the actions to be taken so that principals or employees incorporate these values into their activities and establish the character that will permit them to regards options and make correct decisions in keeping with the business's goals.

Keywords: Theory of Planned Behaviour (TPB); Attitude (ATT); Subjective Norm (SN); Perceived Behavioural Control (PBC); Entrepreneurial Behaviour; Social Psychologists.

\section{Resumen}

El propósito de esta investigación fue analizar las relaciones entre los factores que influyen en la Intención empresarial (EI), utilizando una versión modificada de la teoría del comportamiento planificado (TPB) de Ajzen, considerando la percepción del comportamiento. Este examen dependió de las características demográficas de los participantes y los rasgos de actitud de comportamiento psicosocial (ATT), norma subjetiva (SN) y control conductual percibido (PBC). El establecimiento de un nuevo negocio implica varias formas de acción para lograr los resultados deseados. Esta investigación analiza el emprendimiento como la creación de negocios al participar en un comportamiento racional para optimizar el uso de las tecnologías disponibles y las fuentes financieras. Estas actividades no están estandarizadas: surgen de la imaginación empresarial, la percepción de nuevas oportunidades y la innovación. El objetivo de una empresa no es solo producir y vender bienes o servicios. Una empresa debe determinar los medios apropiados para proporcionarlos y elegir los valores que se adoptarán en el procedimiento para hacerlo. Las empresas también deben identificar las acciones a tomar para que los directores o empleados incorporen estos valores en sus actividades y establezcan el carácter que les permita considerar las opciones y tomar decisiones correctas de acuerdo con los objetivos de la empresa.

Palabras clave: Teoría del comportamiento planificado (TPB); Actitud (ATT); Norma subjetiva (SN); Control conductual percibido (PBC); Comportamiento emprendedor; Psicólogos sociales.

\section{Introduction}

Although the components of attitudes and the motivation elaborate in attitude change have parallels in the entrepreneurship literature, by far the most influential attitude theory has been the theory of reasoned action (Fishbein, M., \& Ajzen, I., 1991), and its successor, the TPB (Ajzen, I., 1991). The theory of planned behavior (TPB) begins with an assumption quite congenial to entrepreneurship, namely, that most important behavior is volitional. Such volitional behavior is presumed to be the product of intentions, which are themselves a function of the person's overall attitude and the "Subjective Norms" that represent social pressure either to perform or not perform the action. Regardless of attitude and subjective norms, intentions will be exercised only if the individual believes that he or she has perceived behavioral control. (See Fig 1) 
The aim of the study was to conduct analyses that are geared towards answering the broad research question, "Are the hypothesized model showing a direct effect of (a) latent factors of attitude, subjective norm, and perceived behavioural control on intention and $(b)$ intention on actual use supported by the observable data?" Structural equation modeling (SEM) was the statistical analysis technique used to test theoretical linkages and the direction of significant relationships among constructs in a hypothesized model.

The overarching research question for this study is this: 'Is the hypothesized model in (Fig 1) showing direct effect between (a) attitude toward the behaviour, subjective norms and perceived behaviour on EI; and (b) perceived behaviour and effect on students' intention to be entrepreneurs; and (c) perceived behaviour and effect on entrepreneurial behaviour?

It should be noted that the analysis was done using Smart PLS and SPSS software. Reason for using Smart PLS software: The most important reason for using this software is that the research variables are not normal.

Before determining the appropriate statistical method for analysis, the hypothesis of the normality of the observations is deduced by using the Kolmogorov-Smirnov statistical test. If the observations do not follow the normal distribution, nonparametric methods are used for statistical analysis. Structural equation modeling (SEM) was used to analyze the observations and to confirm or reject the research hypotheses. In this chapter, the descriptive and inferential analysis of research variables is discussed.

\section{The Theory of Planned Behaviour (TPB)}

As every student of psychology knows, describing human behaviour in all its complexity is a difficult task. It can be approached at many levels, from concern with physiological procedures at one extreme to concentration on social institutions at the other. Social and personality psychologists have tended to focus on an intermediate level, the fully functioning individual whose processing of available information mediates the effects of biological and environmental factors on behaviour. Concepts referring to behavioural dispositions, such as social ATT and personality traits, have played a necessary role in these attempts to predict and describe human behaviour (see [Ajzen, I., 2005; Campbell, D. T., 1963; Sherman, S. J., \& Fazio, R. H., 1953]). Various theoretical frameworks have been proposed to deal with the psychological procedures involved. This special edition of $\mathrm{OB}^{1}$ and Human Decision procedures concentrates on cognitive self-regulation as a necessary dimension of human behaviour. In the pages below, I deal with cognitive self-regulation in the context of a dispositional approach to the prediction of behaviour. A brief examination of past efforts at using measures of behavioural dispositions to predict behaviour is followed by the presentation of a theoretical model, the TPB, in which cognitive selfregulation plays an important part. Recent studies' findings concerning various aspects of the theory are discussed, with particular emphasis on unresolved issues.

\section{Dispositional prediction of human behaviour}

Much has been made of the fact that general dispositions tend to be poor predictors of behaviour in special situations. General ATTs have been assessed concerning organisations and institutions (the church, public housing, student government, one job or employer), minority groups (Blacks, Jews, Catholics), and particular individuals with whom a person might interact (a Black person,

\footnotetext{
${ }^{1}$ Organisational Behaviour
} 
a fellow student). (See [Ajzen, I., \& Fishbein, M., 1977], for a literature review.) The failure of such general ATTs to predict special behaviours directed at the aim of the ATT has produced calls for abandoning the ATT concept (Wicker, A. W., 1969).

Similarly, the low empirical relations between general personality traits and behaviour in special situations, has led theorists to claim that the trait concept, defined as a broad behaviour disposition, is untenable (Mischel, W., 1968) Of particular interest for current purposes is attempted to connect generalized locus of control (Rotter, J. B., 1954; 1966) to behaviours in special contexts. As with other personality traits, the results have been disappointing. For instance, perceived locus of control, as assessed by Rotter's scale, often fails to predict achievement-related behaviour (see [Warehime, R. G., 1972]) or political involvement (see [Lefcourt, H. M., 1981]) in a systematic fashion; and somewhat more specialized measures, such as health-locus of control and achievement-associated locus of control, have not fared much better (see [Lefcourt, H. M., 1982; Wallston, K. A., \& Wallston, B. S., 1981]).

One proposed remedy for the poor predictive validity of ATTs and traits is the aggregation of special behaviours across occasions, situations, and forms of action (See [Epstein, S., 1983; Fishbein, M., \& Ajzen, I., 1974]). The idea behind the principle of aggregation is the assumption that any single sample of behaviour reflects not only the influence of a relevant general disposition but also the influence of various other elements unique to the particular occasion, situation, and action being observed. By aggregating different behaviours, observed on different occasions and in different situations, these other sources of influence tend to cancel each other, with the result that the aggregate represents a more valid measure of the underlying behavioural disposition than any single behaviour. Many studies performed in recent years have demonstrated the workings of the aggregation principle by showing that general ATTs and personality traits do predict behavioural aggregates much better than they predict special behaviours. (See [Ajzen, I., 2005], for a discussion of the aggregation principle and a review of empirical research.)

\section{Accounting for actions in special contexts: based on TPB}

The principle of aggregation, however, does not describe behavioural variability across situations, nor does it permit prediction of a special behaviour in a given situation. It was meant to demonstrate that general ATTs and personality traits are implicated in human behaviour, but that their influence can be discerned only by looking at broad, aggregated, valid samples of behaviour. Their influence on special actions in specific situations is greatly attenuated by the presence of other, more immediate elements. Indeed, it may be discussed that broad ATTs and personality traits have an effect on special behaviours only indirectly by influencing some of the factors that are more closely linked to the behaviour in question (see [Ajzen, I., \& Madden, T. J., 1986]). The current research deals with the nature of these behaviour-special factors in the framework of the $\mathrm{TPB}$, a theory designed to predict and explain human behaviour in special contexts. Because the TPB is explained elsewhere (Ajzen, I., 2005), only brief summaries of its various dimensions are presented here. Relevant empirical findings are considered as each aspect of the theory is argued.

\section{Predicting Behaviour: Intentions and PBC}

The TPB is an extension of the TRA ${ }^{2}$ (See [Fishbein, M., \& Ajzen, I., 1991], [Ajzen, H., \& Fishbein, M., 1980]) made necessary by the fundamental model's limitations in dealing with behaviours over which people have incomplete volitional control. Figure (1) depicts the theory in the form of a structural diagram. For ease of presentation, possible feedback effects of behaviour on the antecedent variables are not shown.

As in the original TRA, a central factor in the TPB is the individual's intention to perform a given behaviour. Intentions are assumed to capture the motivational factors that influence behaviour; they are indications of how hard people are willing to try, of how much of an effort

\footnotetext{
${ }^{2}$ The theory of reasoned action (TRA), aims to explain the relationship between attitudes and behaviors within human action. It is mainly used to predict how individuals will behave based on their pre-existing attitudes and behavioral intentions.
} 
they are planning to exert, in order to perform the behaviour. As a general rule, the stronger the intention to engage in a behaviour, the more likely it should be its performance. It should be clear, however, that a BI can find expression in behaviour only if the behaviour in question is under volitional control, i.e., if the person can decide at will to perform or not perform the behaviour. Although some behaviours may, in fact, meet this requirement quite well, the performance of most rely at least to some degree on such non-motivational factors as availability of requisite opportunities and resources (e.g., time, money, skills, cooperation of others; see [Ajzen, I., \& Driver, B. L., 1991; 1992], for a discussion). Collectively, these factors represent people's actual control over the behaviour. To the extent that a person has the required opportunities and sources, and intends to perform the behaviour, he or she should succeed in doing so. ${ }^{3}$

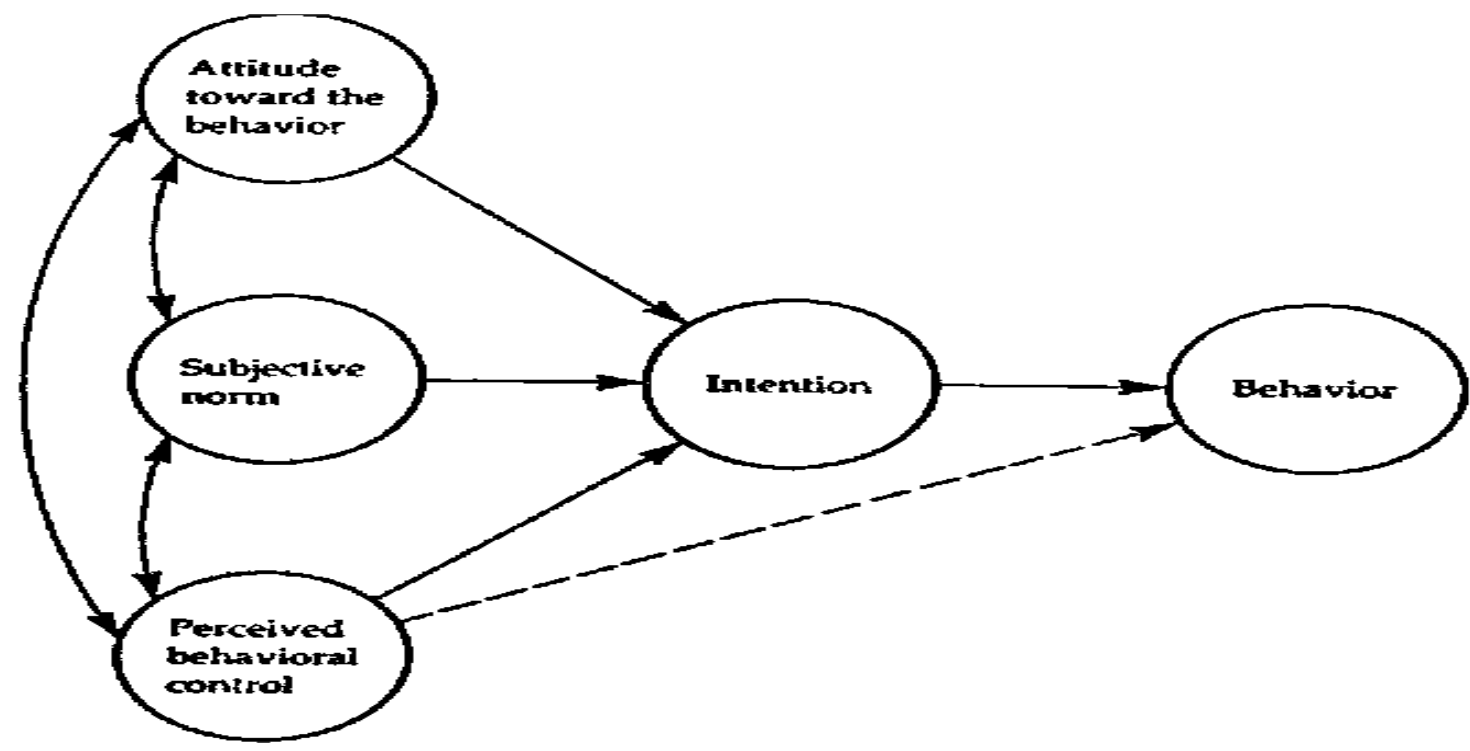

Figure 1. Hypothesized research model analysis

Hypothesized Theoretical Model. This figure illustrates (a) the direction of the relationships of cognition attitude, subjective norm, and perceived behavioural control on behavioural intention; and (b) perceived behaviour on behavioural intention; and (c) perceived behaviour on entrepreneurial behaviour. $\mathrm{CA}=$ Cognition Attitude, $\mathrm{SN}=$ Subjective Norms, $\mathrm{PBC}$ $=$ Perceived Behavioural Control, $\mathrm{BI}=$ Behavioural Intention, $\mathrm{ATT}=$ Attitude, $\mathrm{BEHA}=$ Behaviour.

Concerning the ATT, this construct shows the perceptions of the personal desirability of performing the behaviour (Zhao, H., et al., 2005). ATT depends on individual expectations and

\footnotetext{
${ }^{3}$ The original derivation of the TPB (Ajzen, I., \& Driver, B. L., 1991), defined intention (and its other theoretical constructs) in terms of trying to perform a given behaviour instead of in relation to actual performance. However, early work with the model showed strong correlations between measures of the model's variables that asked about trying to perform a given behaviour and measures that dealt with actual performance of the behaviour (See [Ajzen, I., \& Madden, T. J., 1986], [Schifter, D. E., \& Ajzen, I., 1985]). Since the latter measures are less cumbersome, they have been used in subsequent research, and the variables are now defined more simply in relation to behavioural performance. See, however, Bagozzi and Warshaw (Bagozzi, R. P., \& Warshaw, P. R., 1990) for work on the concept of trying to attain a behavioural goal.
} 
beliefs about the outcomes of the behaviour. This construct allows us to measure the expectations of people in the sample about their ability to do something (Shapero, A., \& Sokol, L., 1982). More specifically, it is referred to as the degree to which a person has a favorable evaluation of the behaviour in question (Ajzen, I., 1985). Individuals form ATTs about a particular behaviour by associating the behaviour accompanied by the likely outcome that will result. If the findings are most desirable, there will be a stronger intention to perform the behaviour. In the case of Entrepreneurial Intention (EI), Attitude toward behaviour $(\mathrm{AB})$ can be considered as the desirability of creating a new firm. In the entrepreneurial context, a positive perception of expected outcomes is typically connected with the act of starting one's own business (Zhao, H., et al., 2005; Shapero, A., \& Sokol, L., 1982; Ajzen, I., 1985; Montano, D. E., \& Kasprzyk, D., 2015; Shook, C. L., \& Bratianu, C., 2010; Di Paola, N., 2016).

The idea that behavioural achievement depends jointly on motivation (intention) and ability (behavioural control) is by no means new. It constitutes the basis for theorizing on such diverse issues as animal learning (Hull, C. L., 1943), level of aspiration (Lewin, K., et al., 1944), performance on psychomotor and cognitive tasks (e.g., [Locke, E. A., 1965; Vroom, V., 1964]), and person perception and attribution (e.g., [Heider, F., 1944; Anderson, N. H., 1974]). It has similarly been suggested that some conception of behavioural control be contained in our more general models of human behaviour, conceptions in the form of "facilitating Factors" (Triandis, H. C., 1977), "the context of opportunity" (Sarver, V. T., 1983), "resources” (Liska, A. E., 1984), or "action control" (Kuhl, J., 1984). The assumption is usually made that motivation and ability interact in their effects on behavioural achievement. Thus, intentions would be expected to influence performance to the extent that the person has behavioural control, and performance should increase with behavioural control to the extent that the person is motivated to try. Interestingly, despite its intuitive plausibility, the interaction hypothesis has received only limited empirical support (see [Locke, E., et al., 1978]). We will return to this issue below.

\section{Perceived Behavioural Control (PBC)}

The importance of actual behavioural control is self-evident: The sources and opportunities available to a person must, to some extent, dictate the likelihood of behavioural achievement. Of greater psychological interest than actual control, however, is the perception of behavioural control and its impact on intentions and actions. PBC plays an important part in the TPB. The TPB differs from the TRA in its addition of PBC. Before considering the place of PBC in the prediction of intentions and actions, it is instructive to compare this construct to other conceptions of control. Importantly, PBC differs significantly from Rotter's (1966) concept of perceived locus of control. Consistent with an emphasis on factors that are directly linked to a particular behaviour, PBC refers to the people's perception of the ease or difficulty of performing the behaviour of interest. Whereas locus of control is a generalized expectancy that remains stable across situations and forms of action, PBC can, and usually does, vary across situations and actions. Thus, a person may believe that, in general, her outcomes are determined by her behaviour (internal locus of control), yet at the same time, she may also believe that her chances of becoming a commercial airplane pilot are very slim (low perceived behavioural control).

Another approach to perceived control can be found in Atkinson's (1964) theory of achievement motivation. An essential factor in this theory is the expectancy of success, defined as the perceived probability of succeeding at a given task. This view is quite similar to PBC in that it refers to a special behavioural context and not to a generalized predisposition. Somewhat paradoxically, the motive to achieve success is defined not as a motive to succeed at a given task but in terms of a general disposition "which the individual carries about him from one situation to another" (Atkinson, J. W., 1964). This general achievement motivation was assumed to mix multiplicatively with the situational expectancy of success as well as with another situationspecific factor, the "incentive value" of success.

The present view of PBC, however, is most compatible with Bandura's (See [Bandura, A., \& Walters, R. H., 1977; Bandura, A., 1977b; 1982]) concept of perceived self- efficacy which "is 
concerned with judgments of how well one can execute courses of action required to deal with prospective situations" (Bandura, A., 1982). Much of our knowledge about the role of PBC comes from the systematic research program of Bandura and his associates (e.g., [Bandura, A., et al., $1977 ; 1980])$. These investigations have shown that peoples behaviour is strongly influenced by their confidence in their ability to perform it (i.e., by PBC). Self- efficacy beliefs can influence the choice of activities, preparation for an activity, effort expended during the performance, as well as thought patterns and emotional reactions (see [Bandura, A., 1991; 2010]). The TPB places the construct of self-efficacy belief or PBC within a more general framework of the relations among beliefs, ATTs, intentions, and behaviour.

According to the TPB, PBC, together with $\mathrm{BI}$, can be used directly to predict behavioural achievement. At least two rationales can be offered for this hypothesis. First, holding intention constant, the effort expended to bring a course of behaviour to a successful conclusion is likely to increase with PBC. For example, even if two individuals have equally strong intentions to learn to ski, and both try to do so, the person who is confident that he can master this activity is more likely to persevere than is the person who doubts his ability. ${ }^{4}$ The second reason for expecting a direct link between PBC and behavioural achievement is that PBC can often be used as a substitute for a measure of actual control. Whether a measure of PBC can substitute for a measure of actual control depends, of course, on the accuracy of the perceptions. PBC may not be particularly realistic when a person has relatively little information about the behaviour, when requirements or available sources have changed, or when new and unfamiliar elements have entered into the situation. Under those conditions, a measure of PBC may add little to the accuracy of behavioural prediction. However, to the extent that perceived control is realistic, it can be used to predict the probability of a successful behavioural attempt (Ajzen, I., 1985).

\section{Predicting Behaviour: Empirical Findings}

According to TPB, the performance of a behaviour is a joint function of intentions and PBC. For accurate prediction, several conditions have to be met. First, the measures of intention and PBC must correspond to (Ajzen, I., \& Fishbein, M., 1977) or be compatible with (Ajzen, I., 2005) the behaviour that is to be predicted. That is, intentions and perceptions of control must be analyzed about the particular behaviour of interest, and the specified context must be the same as that in which the behaviour is to occur. For instance, if the behaviour to be predicted is "donating money to the Red Cross," then we must analyze intentions "to donate money to the Red Cross" (not intentions "to donate money" in general nor intentions "to help the Red Cross"), as well as perceived control over "donating money to the Red Cross." The second condition for accurate behavioural prediction is that intentions and PBC must remain stable in the interval between their analyze and observation of the behaviour. Intervening events may produce changes in intentions or in perceptions of behavioural control, with the effect that the original measures of these variables no longer permit accurate prediction of behaviour. The third requirement for predictive validity has to do with the accuracy of PBC. As noted earlier, the prediction of behaviour from PBC should improve to the extent that perceptions of behavioural control realistically reflect actual control.

The relative importance of intentions and PBC in the prediction of behaviour is expected to vary across situations and different behaviours. When the behaviour/situation affords a person complete control over behavioural performance, intentions alone should be sufficient to predict behaviour, as specified in the TRA. The addition of PBC should become increasingly useful as volitional control over the behaviour declines. Both, intentions and perceptions of

\footnotetext{
${ }^{4}$ It may appear that the individual with high PBC shall also have a stronger intention to learn skiing than the individual with low perceived control. However, as we shoud see below, intentions are influenced by additional factors, and it is because of these other factors that two individuals with different perceptions of behavioural control can have equally strong intentions.
} 
behavioural control, can make significant contributions to the prediction of behaviour, but in any given application, one may be more important than the other, and only one of the two predictors may be needed.

Intentions and Behaviour. Evidence regarding the relation between intentions and actions has been collected concerning many different types of behaviours, with much of the work done in the framework of the TRA. Reviews of this study can be found in a variety of sources (e.g., [Ajzen, I., 2005; Ajzen, I., \& Madden, T. J., 1986; Ajzen, H., \& Fishbein, M., 1980; Canary, D. J., \& Seibold, D. R., 1984; Sheppard, B. H., et al., 1988]). The behaviours involved have ranged from straightforward strategy choices in laboratory games to actions of considerable personal or social significance, such as having an abortion, smoking marijuana, and choosing between candidates in an election. As a general rule, it is found that when behaviours pose no serious problems of control, they can be predicted from intentions with considerable accuracy (see [Ajzen, I., 2005; Sheppard, B. H., et al., 1988]). Good instances can be found in behaviours that involve a choice among available alternatives. For example, people's voting intentions assessed a short time before a presidential election, tend to correlate with actual voting choice in the range of .75 to .80 (see [Fishbein, M., \& Ajzen, I., 1981]). A different decision is at issue in a mother's choice of feeding method (breast versus bottle) for her newborn baby. This choice was found to have a correlation of .82 with intentions expressed several weeks before delivery (Manstead, A. S., 1983).

Perceived Behavioural Control (PBC) and Behaviour. In this research, however, we focus on situations in which it may be necessary to go beyond totally controllable aspects of human behaviour. We thus turn to research conducted in the framework of the TPB, research that has tried to predict behaviour by combining intentions and PBC.

Looking at the first four columns of data, it can be seen that both predictors, intentions, and PBC, correlate quite well with behavioural performance. The regression coefficients show that in the first five studies, each of the two antecedent variables made a significant contribution to the prediction of behaviour. In most of the remaining studies, intentions proved the more important of the two predictors; only in the case of weight loss (See [Schifter, D. E., \& Ajzen, I., 1985; Netemeyer, R. G., et al., 1991]) did perceive behavioural control (PBC) overshadow the contribution of intention. ${ }^{5}$

\section{The role of beliefs in human behaviour}

True to its goal of describing human behaviour, not merely predicting it, the TPB deals with the antecedents of ATTs, SNs, and PBC, antecedents which in the final analysis determine intentions and actions. At the most basic level of description, the theory postulates that behaviour is a function of salient information or beliefs relevant to the behaviour. People can hold a great many beliefs about any given behaviour, but they can attend to only a relatively small number at any given moment (See [Miller, G. A., 1956]). It is these salient beliefs (SBs) that are considered to be the principal determinants of a person's intentions and actions. Three kinds of SBs are distinguished: behavioural beliefs (BBs), which are assumed to influence $A B$, NBs, which constitute the underlying determinants of SNs, and CBs, which provide the basis for perceptions of behavioural control.

\footnotetext{
${ }^{5}$ Intention-behaviour correlations are, of course, not always as high as this. Lower correlations can be the result of unreliable or invalid analysis (see [Sheppard, B. H., et al., 1988]) or, as we should see below, due to problems of volitional control. (See eq. [1])
} 


\section{Behavioural Beliefs (BBs) and Attitudes (ATTs) toward Behaviours (BEHA)}

Most contemporary social psychologists take a cognitive or information-processing approach to ATT formation. This approach is exemplified by Fishbein and Ajzen's (1975) expectancy-value model (EVM) of ATTs. As stated in this model, ATTs improve reasonably from the beliefs people hold about the object of the ATT. Generally speaking, we form beliefs about an object by associating it with special attributes, i.e., with other objects, characteristics, or events. In the case of ATTs toward behaviour, each belief links the behaviour to a particular outcome, or to some other attribute such as the cost incurred by performing the behaviour. Since the attributes that come to be linked to the behaviour are already valued positively or negatively, we automatically and simultaneously acquire an AB. In this fashion, we learn to favor behaviours we believe have largely explained consequences, and we form unfavorable ATTs toward behaviours we associate with the most undesirable consequences. Specifically, the outcome's subjective value contributes to the ATT in direct proportion to the strength of the belief, i.e., the subjective;

$$
\text { (2) } A \propto \sum b_{i} e_{i}
$$

The probability that the behaviour will produce the outcome in question. As shown in Eq. (2), the strength of each salient belief $(b)$ is combined in a multiplicative fashion with the subjective evaluation $(e)$ of the belief's attribute, and the resulting products are summed over, then salient beliefs. A person's ATT $(A)$ is directly proportional $(\%)$ to this summative belief index.

We can explore an ATT's informational foundation by eliciting SBs about the ATT object and assessing the subjective probabilities, and values associated with the different beliefs. Also, by combining the observed values by Eq. (2), we obtain an approximate of the ATT itself, an estimate that represents the respondent's evaluation of the object or behaviour under consideration. Since this estimate is based on SBs about the ATT object, it may be termed a beliefbased measure of ATT if the EVM specified in Eq. (2) is valid, the belief-based measure of ATT should correlate well with a standard measure of the same ATT.

A significant number of researches have, over the years, tested the general EVM of ATT as well as its application to behaviour. In a typical study, a standard, global measure of ATT is obtained, usually by means of an evaluative semantic differential, and this standard measure is then correlated with an estimate of the same ATT based on SBs (e.g., [Fishbein, M., \& Ajzen, I., 1981; Ajzen, I., 1974; Fishbein, M., 2008; Jaccard, J. J., \& Davidson, A. R., 1972; Godin, G., \& Shephard, R. J., 1987; Insko, C. A., et al., 1970; Rosenberg, M. J., 1956]). The results have generally supported the hypothesized relation between SBs and ATTs, although the magnitude of this relation has sometimes been disappointing. Various factors may be responsible for relatively low correlations between SBs and ATTs. First, of course, there is the possibility that the EVM is an inadequate description of the way ATTs are formed and structured. For instance, some investigators (e.g., [Valiquette, C. A., et al., 1988]) have questioned the multiplicative combination of beliefs and evaluations in the EVM of ATT. Most discussions of the model, however, have focused on methodological issues.

Belief Salience. It is not always realized that the EVM of ATT embodied in the theories of reasoned action and planned behaviour postulates a relation between a person's salient belief about the behaviour and his or her ATT toward that behaviour. These SBs must be elicited from the respondents themselves, or in pilot work from a sample of respondents that are representative of the research population. An arbitrarily or intuitively selected set of belief statements will tend to include many associations to the behaviour that are not salient in the population, and a measure of ATT based on responses to such statements need not correlate highly with a standard measure of the ATT in question. Generally speaking, results of empirical investigations suggest that when SBs estimate ATTs, correlations with a standard analyze tend to be higher than when they are 
approximated by an intuitively selected set of beliefs (See [Fishbein, M., \& Ajzen, I., 1991], for a discussion). Nevertheless, as we will see below, correlations between standard and belief-based measures are sometimes of only moderate magnitude even when SBs are used.

Optimal Scaling. A methodological issue of considerable importance that has not received sufficient attention has to do with the scaling of belief and evaluation items. In most applications of the TPB, belief strength is assessed using a 7-point graphic scale (e.g., likely-unlikely) and assessment using a 7-point assessment scale (e.g., good-wrong). There is nothing in the theory, however, to inform us whether responses to these scales should be scored in a unipolar fashion (e.g., from 1 to 7 , or from 0 to 6) or in a bipolar fashion (e.g., from -3 to +3 ). Belief strength (b) is defined as the subjective probability that a given behaviour will produce a particular outcome (See [Fishbein, M., \& Ajzen, I., 1991]). In light of this definition, it would seem reasonable to subject the analyze of belief strength to unipolar scoring, analogous to the 0 -to- 1 scale of objective probabilities. In contrast, evaluations (e), like ATTs, are usually assumed to form a bipolar continuum, from a negative evaluation on one end to a positive evaluation on the other (See [Pratkanis, A. R., 1989], for a discussion of unipolar versus bipolar ATT structures).

From a measurement perspective, however, either type of scoring could be applied with equal justification. Rating scales of the kind used in research on the EVM can at best be assumed to meet the requirements of equal-interval evaluates. As such, it is permissible to apply any LT to the respondents ratings without altering the measure's scale properties (See, e.g., [Dawes, R. M., 1972]). Going from a bipolar to a unipolar scale, or vice versa, is, of course, a simple LT in which we add or subtract a constant from the obtained values. ${ }^{6}$

There is thus no rational a priori criterion we can use to decide how the belief and analysis scales shall be scored (cf., [Schmidt, F. L., 1973]). Holbrook suggested a relatively easy solution to this problem ([Holbrook, M. B., 1977], see also [Orth, B., 1985]). Let B represent the constant to be added or subtracted in the rescaling of belief strength, and $\mathrm{E}$ the constant to be added or subtracted in the rescaling of outcome evaluations. The EVM showed in Eq. (2) can then be rewritten as;

$$
A \propto \sum\left(b_{i}+B\right)\left(e_{i}+E\right)
$$

Expanded, this becomes;

$$
A \propto \sum b_{i} e_{i}+B \sum e_{i}+E \sum b_{i}+B E
$$

moreover, disregarding the constant $\mathrm{BE}$, we can write:

$$
A \propto \sum b_{i} e_{i}+B \sum e_{i}+E \sum b_{i}
$$

Note. $A=$ semantic differential measure of ATT, Xblel belief-based measure of ATT, $b=$ belief strength, $e=$ outcome evaluation, $B=$ optimal rescaling constant for belief strength, $E=$ optimal rescaling constant for outcome evaluation.

To approximate the rescaling parameters $B$ and $E$, we regress the standard ATT analysis, which serves as the criterion, on $\sum b_{i} e_{i}, \sum b_{i}$ and $\sum e_{i}$; and then divide the unstandardized regression coefficients of $\sum b_{i}$ and $\sum e_{i}$, by the coefficient obtained for $\sum b_{i} e_{i}$, The resulting value for the coefficient of $\sum e_{i}$, provides a least-squares estimate of $B$, the rescaling

\footnotetext{
${ }^{6}$ Note. however, that a LT of $\mathrm{b}$ or e results in a non-LT of the $\mathrm{b} x$ e product term.
} 
constant for belief strength, and the value for the coefficient of $\sum b_{i}$ serves as a least-squares estimate of $E$, the rescaling constant for outcome evaluation. ${ }^{7}$

An Empirical Illustration. To illustrate the use of optimal rescaling coefficients, we turn to a recent study on leisure behaviour [Ajzen, I., \& Driver, B. L., 1991]. In this study, college students completed a questionnaire concerning five different leisure activities: spending time at the beach, outdoor jogging or running, mountain climbing, boating, and biking. A standard semantic differential scale was used to assess global evaluations of each activity. For the beliefbased ATT measures, pilot subjects had been asked to list the costs and benefits of each leisure activity. The most frequently mentioned beliefs were retained for the main study. Concerning spending time at the beach, for instance, the SBs included such costs and benefits as developing skin cancer and meeting people of the opposite sex.

\section{NBs and SNs}

NBs are considered with the likelihood that essential referent individuals or groups approve or disapprove of performing a given behaviour. The strength of each NBs (n) is multiplied by the person's motivation to comply (in) with the referent in question, and the subjective norm ( $\mathrm{SN}$ ) is directly proportional to the sum of the resulting products across then salient referents, as in Eq. (6):

(6)

$$
S \mathrm{~N} \propto \sum n_{i} m_{i}
$$

A global measure of $\mathrm{SN}$ is usually obtained by asking respondents to rate the extent to which "important others" would approve or disapprove of their performing a given behaviour. Empirical investigations have shown that the best correspondence between such global measures of SN and belief-based measures is usually obtained with bipolar scoring of NBs and unipolar scoring of motivation to comply (Ajzen, I., \& Madden, T. J., 1986; Ajzen, H., \& Fishbein, M., 1980). With such scoring, correlations between belief-based and global estimates of the SN are usually in the range of .40 to .80 , not unlike the findings concerning ATTs (see, e.g., [Ajzen, I., \& Madden, T. J., 1986; Fishbein, M., \& Ajzen, I., 1981; Otis, J., et al., 1990]).

As an illustration, we turn again to the study on leisure behaviour [Ajzen, I., \& Driver, B. L., 1991]. The salient referents for the five leisure activities elicited in the pilot study were friends, parents, boyfriend/girlfriend, brothers/sisters, and other family members. Concerning each referent, respondents rated, on a 7-point scale, the degree to which the referent would approve or disapprove of their engaging in a given leisure activity. These NBs were multiplied by the motivation to comply with the referent, a rating of how much the respondents cared whether the referent approved or disapproved of their leisure activities.

\section{CBs and PBC}

Among the beliefs that ultimately determine intention and action, there is, as stated in TPB, a set that deals with the presence or absence of requisite resources and opportunities. These CBs may be based in part on experience with the behaviour, but they will usually also be influenced via second-hand information about the behaviour, by the experiences of acquaintances and friends, and by other factors that increase or reduce the perceived difficulty of performing the behaviour in question. The more sources and opportunities individuals believe they possess, and the fewer obstacles or impediments they anticipate, the greater should be their perceived control over the behaviour. Specifically, as shown in Eq. (4.6), each control belief (c) is multiplied by the

\footnotetext{
${ }^{7}$ Note. significant; all other correlations $\mathrm{p}<.05$.
} 
perceived power (p) of the particular control factor to facilitate or inhibit the performance of the behaviour, and the resulting products are summed across then salient CBs to produce the perception of behavioural control (PBC). Thus, just as beliefs concerning the consequences of a behaviour are viewed as determining $\mathrm{AB}$, and NBs are viewed as determining SNs, so beliefs about resources and opportunities are viewed as underlying PBC.

$$
P B C \propto \sum p_{i} c_{i}
$$

As of today, only a handful of studies have examined the relationship between specific CBs and PBC (e.g., [Ajzen, I., \& Madden, T. J., 1986]). Global assessments of the perceived ease or difficulty of engaging in each of the five leisure activities were correlated with belief-based measures of PBC. Concerning outdoor running or jogging, for instance, control factors included being in poor physical shape and living in an area with good jogging weather.

In conclusion, inquiries into the role of beliefs as the foundation of ATT toward a behaviour, SN, and PBC have been only partly successful. Most troubling are the generally moderate correlations between belief-based indices and other, more global measures of each variable, even when the components of the multiplicative terms are optimally rescored. Note that responding to the belief and valuation items may require more careful deliberations than does responding to the global rating scales. It is, therefore, possible that the global measures evoke a relatively automatic reaction, whereas the belief- related items evoke a relatively reasoned response. Some evidence, not dealing directly with EVMs, is available in research on the prediction of intentions in the context of the TRA (Ellen, P. S., \& Madden, T. J., 1990). The study manipulated the degree to which respondents had to concentrate on their ratings of ATTs, SNs, and intentions concerning a variety of different behaviours. This was done by presenting the questionnaire items organised by behaviour or in random order, and by using a paper and pencil instrument versus a computer-administered format. The prediction of intentions from ATTs and SNs was better under conditions that required careful responding (random order of items, computer-administered) than in the comparison conditions. ${ }^{8}$

Our discussion of the relationship between global and belief-based analysis of ATTs is not meant to question the general idea that beliefs influence ATTs about the ATT object. This idea is well supported, especially by an experimental study in the area of persuasive communication: A persuasive message that attacks beliefs about an object is typically found to produce changes in ATTs toward the object (See [McGuire, W. J., 1985; Petty, R. E., \& Cacioppo, J. T., 1986]). It is highly likely that persuasive communications directed at particular normative or CBs will influence SNs and PBC. Instead of questioning the idea that beliefs have a causal effect on ATTs, SNs, and PBC, the moderate correlations between global and belief-based measures suggest that the expectancy-value formulation may fail adequately to describe the process whereby individual beliefs combine to produce the global response. Efforts need to be directed toward improving alternative models that could be used better to describe the relations between beliefs on the one hand and the global constructs on the other. In the pages below, we consider several other unresolved problems related to the TPB.

\section{The sufficiency of the TPB}

The TPB distinguishes between three types of BBs, normative, and control and between the related constructs of ATT, SNs, and PBC. The necessity of these distinctions, especially the distinction between behavioural and NBs (and between ATTs and SNs), has sometimes been questioned (e.g., [Miniard, P. W., \& Cohen, J. B., 1981]). It can reasonably be discussed that all beliefs associate the behaviour of interest with an attribute of some kind, be it an outcome, a normative expectation, or a source needed to perform the behaviour. It should thus be possible to

\footnotetext{
8 Interestingly, this research failed to replicate the results of Budd's (1987) experiment in which randomization of items drastically decrease the correlations among the constructs in the TPB. A recent research done by van den Putte and Hoogstraten (1990) also failed to corroborate Budd's findings.
} 
integrate all beliefs about a given behaviour under a single summation to achieve an assessment of the overall behavioural disposition.

The essential issue with such a method is that it obscures qualifications that are of intrigue, both from a hypothetical and from a viable perspective. Hypothetically, individually examine of a BEHA (ATT), socially anticipated method of direct ( $\mathrm{SN})$; furthermore, self-adequacy concerning the behaviour (PBC) are altogether different ideas, every one of which has a basic spot in social and conduct ponders. Furthermore, the huge number of concentrates on the TRA and the TPB has set up the utility of the qualifications by means of outlining that the various builds remain in unsurprising relations to expectations and behaviour. ${ }^{9}$

Maybe of more prominent significance is the plausibility of making further differentiations between new sorts of beliefs and related dispositions. The TPB is, in principle, open to the inclusion of additional predictors if it can be illustrated that they capture a significant proportion of the variance in intention or behaviour after the theory's current variables have been taken into account. The TPB, in fact, expanded the original TRA by adding the concept of PBC.

\section{Personal or MNs}

It has some of the time been offered that, in any event in certain context, we have to consider perceived not only social pressures as well as personal feelings of moral obligation or duty to perform or decline to play out, a specific behaviour (See [Gorsuch, R. L., \& Ortberg, J., 1983; Pomazal, R. J., \& Jaccard, J. J., 1976; Schwartz, S. H., \& Tessler, R. C., 1972]). Such moral obligations would be expected to affect intentions, in parallel with ATT, SNs (social), and PBC. In a recent study of college students (Beck, L., \& Ajzen, I., 1991), we investigated this issue in the context of three deceptive behaviours: cheating on a test or investigation, shoplifting, and misleading escape stepping through an exam or turning in a task on schedule. It appeared to be sensible to recommend that ethical issues may take on included remarkable salience concerning behaviours of this sort and that a proportion of apparent good commitment could add prescient capacity to the model.

\section{Affect versus Assessment}

Just as it is possible to distinguish among different types of normative pressures, it is possible to distinguish among different kinds of ATTs. In developing the TRA, no clear distinction was drawn between effective and evaluative responses to behaviour. Any usual reaction that could be located along a dimension of favorability from negative to positive was considered an indication of ATT (See [Fishbein, M., \& Ajzen, I., 1991; Ajzen, I., \& Madden, T. J., 1986; Ajzen, H., \& Fishbein, M., 1980]). Some investigators, however, have offered that it is useful to distinguish among "hot" and "cold" cognitions (Abelson, 1963) or between evaluative and affective judgments (See [Abelson, R. P., et al., 1982], [Ajzen, I., \& Timko, C., 1986]). ${ }^{10}$ This distinction was evaluated in the research on the leisure activities of college students mentioned earlier (See [Ajzen, I., \& Driver, B. L., 1991; 1992]).

In addition to the perceived costs and advantages of performing a given leisure activity (evaluative judgments), the study also analyzed beliefs about positive or negative feelings derived from the activity (effective judgments). A questionnaire survey assessed evaluative and affective beliefs concerning the five leisure activities: spending time at the beach, outdoor jogging or

\footnotetext{
${ }^{9}$ Of course, even as we accept the proposed distinctions, we can imagine other kinds of relations among the different theoretical constructs. For instance, it has been suggested that, in certain situations, PBC functions as a precursor to ATTs and SNs (Van Ryn, M., 1991) or that ATTs not only influence intentions but also have a direct effect on behaviour (Bentler, P. M., \& Speckart, G., 1979).

${ }^{10}$ In a related manner, Bagozzi $(1986,1989)$ has drawn a distinction among moral (good/ bad) and affective (pleasant/unpleasant) attitudes (ATTs) toward a behaviour (BEHA).
} 
running, mountain climbing, boating, and biking. For instance, concerning spending time at the beach, beliefs of an evaluative nature included, as mentioned earlier, improving skin cancer and meeting people of the opposite sex, while between the beliefs of an effective nature were feeling the heat and sun on your body and watching and listening to the ocean. Consistent with the EVM of ATT, respondents rated the likelihood of each consequence as well as its subjective value, and the products of these ratings were summed over the set of SBs of an evaluative nature and the set of SBs of an effective nature. Also, the respondents were asked to rate each activity on a 12-item semantic differential containing a variety of evaluative (e.g., harmful beneficial) and practical (e.g., pleasant unpleasant) adjective pairs.

A factor analysis (FA) of the semantic differentials revealed the two expected factors, one evaluative and the other effective in tone. Of greater interest, the summative index of evaluative beliefs correlated via the evaluative, but not with the useful, semantic differential; and the sum over the affective beliefs correlated with the effective, but not with the evaluative, semantic differential. (Evidence for the discriminant validity of the distinction among evaluation and effect was also stated by Breckler and Wiggins, 1989).

Despite this evidence for the convergent and discriminant validities of the active and evaluative measures of beliefs and ATTs, using the two separate measures of ATT did not significantly improve the prediction of leisure intentions.

\section{The Role of Past Behaviour}

The question of the model's sufficiency can be addressed at a more usual level by considering the theoretical limits of predictive accuracy (See [Beck, L., \& Ajzen, I., 1991]). If all factors, whether internal to the individual or external that determine a given behaviour are known, then the behaviour can be predicted to the limit of measurement error. So long as this set of elements remains unchanged, the behaviour also remains stable over time. The dictum, "past behaviour is the best predictor of future behaviour" will be recognized when these conditions are met.

Under the assumption of stable determinants, an analysis of past behaviour can be used to test the sufficiency of any model designed to predict future behaviour. A sufficient model contains all important variables in the set of determinants and thus accounts for all non-error variance in the behaviour. The addition of past behaviour should not significantly improve the prediction of later behaviour. Conversely, if past behaviour is found to have a significant residual effect beyond the predictor variables contained in the model, it would suggest the presence of other elements that have not been accounted for. The only reservation that shall be added is that evaluates of past, and later behaviour may have common error variance not shared via measures of the other variables in the model. This is particularly likely when behaviour is observed while other variables are assessed using verbal self-reports, but it can also occur because self-reports of behaviour are often elicited in a format that differs substantially from the remaining items in a survey. We would thus often envisage a small, but possibly significant, residual influence of past behaviour even when the theoretical model is, in fact, sufficient to predict future behaviour (see also [Dillon, W. R., \& Kumar, A., 1985]). ${ }^{11}$

Some investigators (e.g., [Bentler, P. M., \& Speckart, G., 1979; Fredricks, A. J., \& Dossett, D. L., 1983]) have suggested that past behaviour is included as a substantive predictor of later behaviour, equivalent to the other independent variables in the model. As stated in these theorists, prior behaviour has an impact on later behaviour that is independent of the effects of beliefs, ATTs, SNs, and intentions. Especially, the assumption usually made is that repeated performance of behaviour results in the establishment of a habit; behaviour at a later time then occurs at least in part habitually, without the mediation of ATTs, SNs, perceptions of control, or intentions. It

11 Dillon and Kumar (1985) pointed out that SEM, such as LISREL, can be used to test this idea by permitting correlated errors among prior and later behaviour. Most of the data presented in the present article could not be submitted to such analyses because of the absence of multiple indicators for the different constructs involved. 
must be recognized, however, that although past behaviour may well reflect the effect of factors that influence later behaviour, it can usually not be considered a causal factor in its own right (See [Ajzen, I., 1987]). Nor can we just assume that past behaviour is a valid measure of habit; it may, and usually does, reflect the influence of many other internal and external factors. Only when a habit is defined independently of (past) behaviour can it legitimately be added as an explanatory variable to the theory of planned behaviour. An analyze of habit thus defined would presumably capture the residues of past behaviour that have established a habit or tendency to perform the behaviour on future occasions. ATTs are, of course, such residues of experience (cf., [Campbell, D. T., 1963]), as are SNs and perceived self-efficacy. The distinctive contribution of habit would lie in finding a residue of experience that leads to habitual rather than reasoned responses.

In sum, past behaviour is best treated not as a measure of habit but as a reflection of all factors that determine the behaviour of interest. The correlation between past and later behaviour is an indication of the behaviour's stability or reliability, and it represents the ceiling for a theory's predictive validity. If an important factor is missing in theory being tested, this would be indicated by a significant residual effect of past on later behaviour. Such residual effects could reflect the influence of habit if the habit is not reported in theory, but it could also be due to other factors that are missing.

Some researches have examined the role of past behaviour in the context of the TRA. Although past behaviour was in these studies treated as a measure of habit, their results can better be considered a test of the theory's sufficiency. Because the intention is the only immediate precursor of behaviour in the TRA, the simplest test of the model's sufficiency is obtained by regressing later on past behaviour after the effect of intention has been extracted. Bentler and Speckart (1979) were the first to look at the residual effect of past behaviour in the context of the TRA. Using SEM, they showed that a model which includes a direct path from prior behaviour to later behaviour provided a significantly better fit to the data than did a model representing the TRA in which the effect of past on later behaviour is assumed to be mediated by intention. Similar results were later stated by Bagozzi (1981) and by Fredricks and Dossett (1983). ${ }^{12}$ (See also [Bagozzi, R. P., \& Warshaw, R. R., 1990; Bagozzi, R. P., \& Warshaw, P. R., 1990]).

These findings imply that even though the TRA accounted for considerable proportions of variance in behaviour, it was not sufficient to describe all systematic variance. One possible reason, of course, is that this theory lacks the construct of perceived self-efficacy or behavioural control. Experience with behaviour is the most important source of information about behavioural control (Bandura, A., 1986). It thus stands to reason that PBC can play an important role in mediating the effect of past on later behaviour.

\section{Inferential Statistical Analysis of the Variables}

In this section, all of the related inferential statistics which is related to our models are reported as follows:

Examining the normality of the questionnaire variables:

Data were analyzed using the Kolmogorov-Smirnov statistical test.

$\boldsymbol{H}_{0}$ : Data have a normal distribution.

$\boldsymbol{H}_{1}$ : The data does not have a normal distribution.

\footnotetext{
12 These research's also tested the theory's assumption that the effect of ATTs on BEHA is mediated by intention, with rather inconclusive results. In a recent research, Bagozzi, Baum- gartner, and Yi (1989) found that direct links between ATTs and BEHA, unmediated by intention, may at least in part reflect methodological problems (Bagozzi, R. P., et al., 1989).
} 
Table 1.

Examining the normality of the questionnaire variables

\begin{tabular}{cccc}
\hline Result & Sig. & Kolmogorov Smirnov test & Variable \\
\hline Abnormal & 0.000 & 2.907 & Behaviour \\
\hline Abnormal & 0.011 & 1.607 & Behaviour Intention \\
\hline Abnormal & 0.000 & 2.302 & Cognition Attitude \\
\hline Abnormal & 0.002 & 1.884 & Perceived Behavioural Control \\
\hline Abnormal & 0.009 & 1.647 & Subjective Norms \\
\hline
\end{tabular}

According to the above table (1), the significance level of the Kolmogorov - Smirnov test is less than 0.05 . Therefore, the $H_{l}$ hypothesis is confirmed that the distribution of all variables in this statistical sample is abnormal. According to the results of the Kolmogorov-Smirnov test, since all of the variables of the questionnaire are abnormal, Smart PLS software is used to study the conceptual model and perform structural equations and to evaluate the measurement models.

In psychology, the theory of planned behaviour (abbreviated TPB) is a theory that links one's beliefs and behaviour.

The theory states that intention toward behaviour, subjective norms, and perceived behavioural control, together shape an individual's behavioural intentions and behaviours.

The concept was proposed by Icek Ajzen to improve the predictive power of the theory of reasoned action by including perceived behavioural control (Ajzen, I., 1991). It has been applied to studies of the relations among beliefs, attitudes, behavioural intentions, and behaviours in various fields such as advertising, public relations, advertising campaigns, healthcare, sport management, and sustainability.

In order to analyze models goodness, we need to evaluate the three above criteria.

1. Measurable Models Goodness of Fit

2. Structure Model Goodness of Fit

3. Total Model Goodness of Fit

\section{Measurable Models Goodness of Fit}

One of the most comprehensive and useful methods that authors often use to select the type of measurement models in their conceptual model of research is the four steps method, which stated by Fizan and et al. (2018). These four rules for constructive and reflective models are as follows:

1. For the cause and effect relationship between structure and index. In the constructive model, the relationship between cause and effect is drawn from the questionnaire to the research variable. Whereas in the reflective model, this direction is from variable questions to the questionnaire. In this research, our model is a reflective model. 
2. Cross-Correlation between questions of each variable. In the constructive model, the cross-correlation between the questions is not certain, whereas, in the reflective model, the questions should have a high correlation to each other.

3. Change questions simultaneously. In the one constructive model, the change in one question does not necessarily lead to the change in the other questions, whereas in the reflective model, it is expected that by changing one question, the effects of the change also appear in all the other questions.

4. Predictions and Outcomes of a Variable Question. In the constructive model, the questions do not necessarily have the same predictions and outcomes, while the questions in the reflective model have the same predictions and consequences.

\section{Structure Model Goodness of Fit}

After examining the fit of the measurement models, it is time to fit the structural model of the research. As mentioned earlier, unlike measurable models goodness of fit, the structural model's goodness of fit section does not deal with questions (Observed Variables), and only the latent variable associated with the relationships between them are examined.

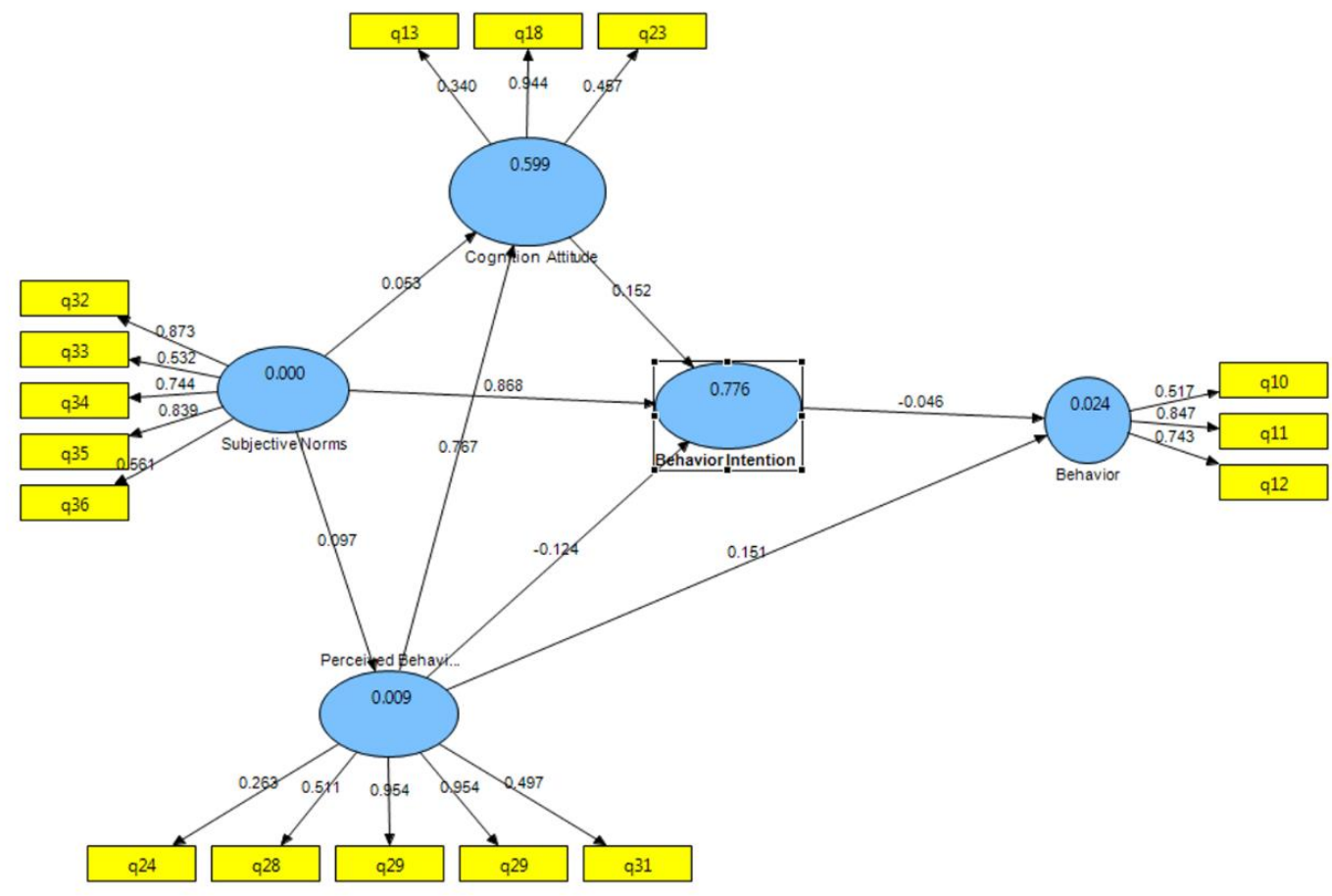

Figure 2. structural model goodness of fit

\section{Significant coefficients $t$ (t-values)}

Several criteria are used to investigate the model goodness of fit in the structural model of the research. The most basic criterion for measuring the relationship between variables in the structural model is the significant numbers $t$. If these values are higher than 1.96, the relationship between the variables is confirmed, and the hypotheses confirmed at the confidence level of 0.95 . 
It should be noted, however, that the numbers represent only the accuracy of the relationship, and the severity of the relationship between the variables cannot be measured.

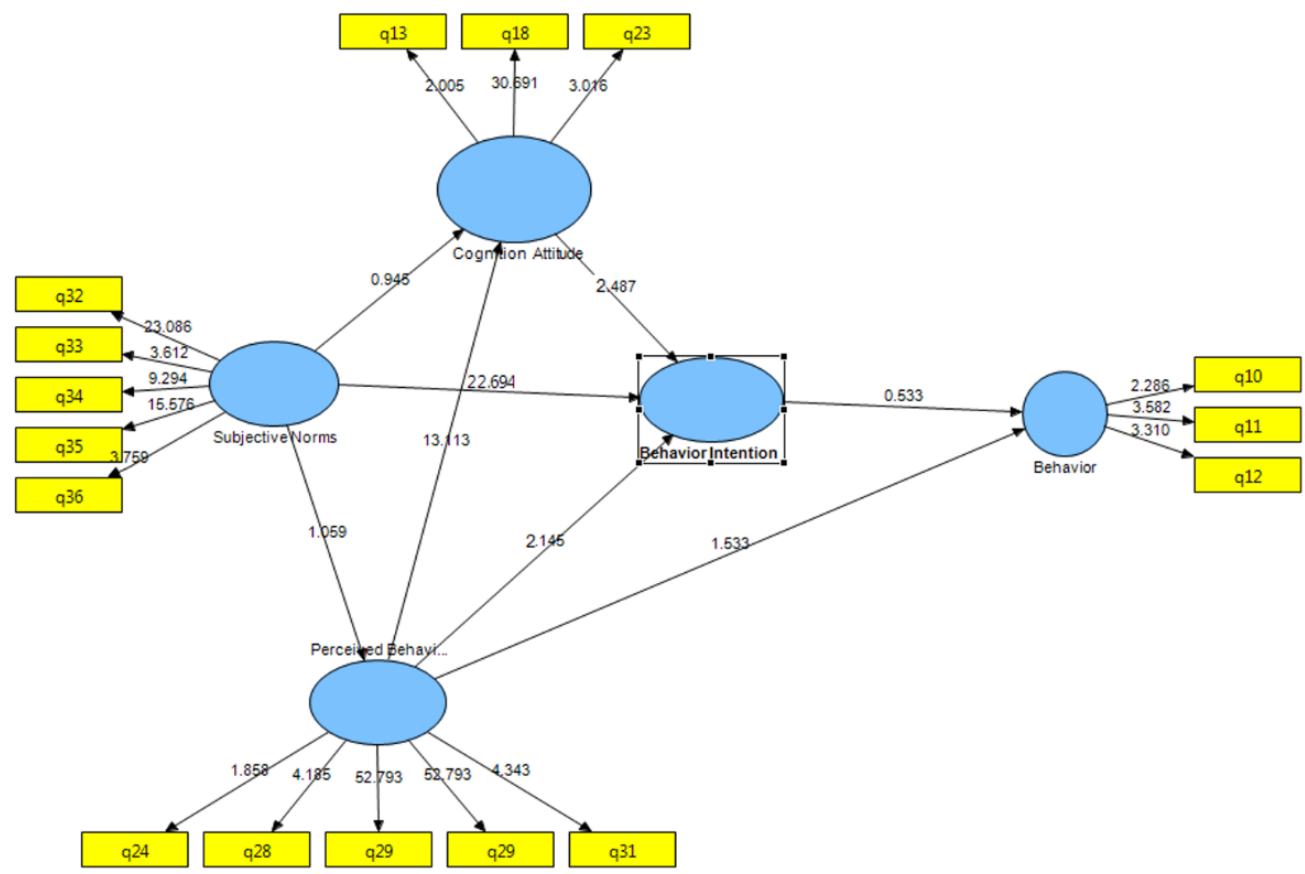

Figure 3. Structural Equation Model goodness of fit with Significant Coefficient t

According to the above two figures (2, and 3), the T-value of the 8 relationships of the variables related to the research hypotheses is greater than 1.96 for the four relationships, indicating that 4 relationships have been confirmed. This means that the model has very good fitness and is acceptable.

\section{$\mathbf{R}$ Squares or $\mathbf{R}^{2}$ criterion}

$\mathrm{R}^{2}$ is a criterion used to connect the measurement and structural parts of structural equation modeling and indicates the effect that an exogenous or independent variable has on an endogenous or dependent variable. One of the main advantages of the partial least squares (PLS) method is that it can reduce errors in measurement models or increase the variance between variables and questions.

This criterion is used to investigate the fit of the structural model in research of $\mathrm{R}^{2}$ coefficients related to endogenous (dependent) model variables. $R^{2}$ is a measure indicating the impact of an exogenous variable on an endogenous variable, and the three values of $0.19,0.33$, and 0.67 are considered as the criterion for weak, medium and strong values.

The value of $\mathrm{R}^{2}$ for the exogenous or independent variables is zero (See table 2.) 
Table 2.

Analyzing $R^{2}$

\begin{tabular}{cc}
\hline R Square & \\
\hline 0.023907 & Behaviour \\
\hline 0.775642 & Behaviour Intention \\
\hline 0.598577 & Cognition Attitude \\
\hline 0.009313 & Perceived Behavioural \\
\hline 0.023907 & Subjective Norms \\
\hline
\end{tabular}

According to the above table (2, and 3 ), the value of $\mathrm{R}^{2}$ for the dependent variables is medium and weak.

\section{Total Model goodness of fit}

The total model consists of both parts of the measurement and structural model, and by verifying its fitness, the goodness of fit test for the model will be complete.

\section{GOF Index for the first model (Main Model)}

The GOF index relates to the general part of structural equation models. This means, by this criterion, the researcher can control the fitness of the whole section after examining the fitness of the measurement section and the structural part of his/her total research model.

Table 3.

Analyzing $R^{2}$ based on communality

\begin{tabular}{ccc}
\hline Communality & R Square & Variables \\
\hline 0.512067 & 0.023907 & Behaviour \\
\hline 0.529149 & 0.775642 & Behaviour Intention \\
\hline 0.404915 & 0.598577 & Cognition Attitude \\
\hline 0.479773 & 0.009313 & Perceived Behavioural \\
\hline 0.523557 & 0.023907 & Subjective Norms \\
\hline 0.489892 & 0.286269 & Average \\
\hline
\end{tabular}

(8)

$$
G O F=\sqrt{0.489 \times 0.2862}=0.375
$$


Considering the three values of $0.01,0.25$, and 0.36 introduced as a low, medium, and strong values for GOF and the obtained value of 0.375 for GOF, it shows a good overall fitness for the model (See table 4.).

Table 4.

Final model fitness index

\begin{tabular}{|c|c|c|c|c|}
\hline Result & $\begin{array}{c}\text { The value } \\
\text { obtained in the } \\
\text { model }\end{array}$ & Ideal value & Acceptable value & Index name \\
\hline Acceptable & 0.727 & $.95 \leq G F I \leq 1.00$ & $.80 \leq G F I<.95$ & Goodness of Fit Index (GFI) \\
\hline Acceptable & 0.845 & $\begin{array}{c}.90 \leq \mathrm{AGFI} \leq \\
1.00\end{array}$ & $.80 \leq \mathrm{A} G F I<.95$ & Adjusted Goodness-of-Fit Index (AGFI) \\
\hline Acceptable & 0.041 & $0 \leq R M R \leq .05$ & $0<R M R \leq .10$ & Root Mean square Residual (RMR) \\
\hline Acceptable & 0.875 & $.97 \leq C F I \leq 1.00$ & $.90 \leq C F I<.97$ & Comparative Fit Index (CFI) \\
\hline Acceptable & 0.801 & $.90 \leq \mathrm{N} F I \leq 1.00$ & $.80 \leq \mathrm{N} F I<.90$ & Normed Fit Index (NFI) \\
\hline Acceptable & 0.045 & $0 \leq R M S E A \leq .05$ & $\begin{aligned} .05 & <R M S E A \\
& \leq .08\end{aligned}$ & $\begin{array}{l}\text { Root Mean Square Error of Approximation } \\
\text { (RMSEA) }\end{array}$ \\
\hline Ideal & 0.779 & $\begin{array}{l}.60 \leq P G F I \leq \\
1.00\end{array}$ & $.50 \leq P G F I<.60$ & $\begin{array}{l}\text { Parsimonious Goodness-Of-Fit Index } \\
\text { (PGFI) }\end{array}$ \\
\hline Ideal & 0.714 & $\begin{array}{l}.60 \leq P N F I \leq \\
1.00\end{array}$ & $.50 \leq P N F I<.60$ & Parsimonious Normed Fit Index (PNFI) \\
\hline
\end{tabular}

The GFI index is one of the comparative indices with a value greater than 0.7 , which indicates the good fitness of the model for the data. The obtained GFI value was 0.727 for the model indicating good fitness of the model.

The residual matrix is one of the ordinary matrices that can be used to evaluate both general fit (formulated model) and partial fit (parameters defined between two variables). The RMR for the model is 0.041 , which is suitable for the quantitative model.

The CFI is one of the comparative indices that values between 0.9 and 0.97 are considered acceptable, and values above 0.875 are interpreted as good fitness for the model.

Like the RMR index, the RMSEA is based on residual matrix analysis. Acceptable models have a value of 0.045 or smaller for this index. The fitting of models with values above 0.1 is poorly estimated. The RMSEA value for this model is 0.045 , indicating that the model is acceptable.

\section{Conclusion and Discussion}

In this research, I have tried to show that TPB provides a useful conceptual framework for dealing with the complexities of human social behaviour. The theory incorporates some of the central 
concepts in the social and behavioural sciences, and it defines these concepts in a way that permits prediction and understanding of particular behaviours in specified contexts. ATTs toward the behaviour, SNs concerning the behaviour, and perceived control over the behaviour are usually found to predict BIs with a high degree of accuracy. In turn, these intentions, in combination with PBC, can account for a considerable proportion of variance in behaviour.

At the same time, there are still many problems that remain unresolved. The theory of planned behaviour traces ATTs, SNs, and PBC to an underlying foundation of beliefs about the behaviour. Although there is plenty of evidence for significant relations among BBs and ATTs toward the behaviour, between NBs and SNs, and between CBs and perceptions of behavioural control, the exact form of these relations is still uncertain. The most widely adopted view, which describes the nature of the relations in terms of expectancy-value models, has received some support, but there is much room for improvement. Of particular concern are correlations of only moderate magnitude that are frequently observed in attempts to relate belief-related measures of the theory's constructs to other, more global measures of these constructs. Optimally rescaling measures of belief strength, outcome assessment, motivation to comply, and the perceived power of control factors can help overcome scaling limitations, but the observed gain in correlations among global and belief-related evaluates insufficient to deal via the problem.

From a general view, however, application of the TPB to a particular area of interest, be it problem drinking (Schlegel, R. P., et al., 1992), leisure behaviour [Ajzen, I., \& Driver, B. L., 1991; 1992], or condom use (Otis, J., et al., 1990), provides a host of information that is extremely useful in an attempt to understand these behaviours, or to implement interventions that will be effective in changing them (Van Ryn, M., 1991). The intention, the perception of behavioural control, $\mathrm{AB}$, and $\mathrm{SN}$ each reveals a different aspect of the behaviour, and each can serve as a point of attack in attempts to change it. The underlying foundation of beliefs provides the detailed descriptions needed to gain substantive information about a behaviour's determinant. It is at the level of beliefs that we can learn about the unique factors that induce one person to engage in the behaviour ${ }^{13}$ of interest and to prompt another to follow a different course of action.

\section{Boundaries, limitations, and directions for future research}

The method of data collection using online surveys may limit the study through a lack of participant response and unavailability of internet capacity. Other key limitations of the study may be the restricted sample of educators obtained from some universities only, the time given to complete the surveys, and the online objective format of the survey that will not accommodate collecting a range of responses. The study was limited to responses about attitude, subjective norm, perceived behavioural control based on a specific measurement scale. A potential threat to the external validity of this study was the fact that all of the nurse educators who participated taught in one particular geographical region that may affect the generalizability of the results.

Although specific information regarding the construction of a questionnaire for TPB was adhered to, internal validity could be threatened by substituting specific language to match the behaviour suitable for the context of this study.

\footnotetext{
${ }^{13}$ Meyer et al. (2004) also suggests two types of loyalty- one attitudinal and the other behavioural. However, they conclude that behavioural loyalty is more important to the organisation and suggest that attitudinal loyalty leads to behavioural loyalty. According to Wan (2012), employee loyalty implies psychological attachment or commitment to the organisation and the employees' willingness to remain with the organization. Hart and Thompson (2007) also insist on the psychological aspect of employee loyalty and their conscious decision to stay and contribute to the organisation (Hart, D. W., \& Thompson, J. A., 2007; Ganic, E., et al., 2018).
} 
Careful analysis of the questionnaire items should be performed, as some problems with their wording may have occurred. More generally, reversed items have tended to be eliminated from the analysis. Therefore, though they may have been useful to avoid acquiescence problems, they may present some other weaknesses. In particular, the social valuation seems to present additional difficulties that have to be solved. The revision of the questionnaire is clearly needed in this respect. A second limitation derives from the characteristics of the sample selected. New research should be performed on a sample extracted from the general adult population. In particular, potential or nascent entrepreneurs should be analyzed to confirm these results.

Like most empirical research, our study has boundaries and limitations that need to be borne in mind when considering its implications. First, because of the case study character of the investigation, we rely on a relatively small sample, which should not be seen as representative for the case country or generalizable to other post-socialist economies. Moreover, we focus on a very particular population group, the farmer, and his/her intent to start a non-farm business. Contrasting the perceptions of the urban population and of developed country respondents would be desirable, as well as comparing farm- with nonfarm business start-up intentions. Second, regardless of the causation direction suggested by the theory, we cannot claim causation because of the cross-sectional character of our data. Any statements implying effects or impact should be treated with caution. Third, our operationalization of the behavioural perception construct focused on bribing, but bribing is just one of many facets of behaviour. More explorative research is needed to fine-tune the measurement of this understudied background factor. Possible extensions could include, for example, the issues of legitimacy and reliance on personal contacts.

\section{Notes:}

1. Results of the present paper are significantly connected with the Ph.D. dissertation of Mohammad Heydari, which was written at the Nanjing University of Science and Technology entitled: "A Cognitive Basis Perceived Corruption and Attitudes Towards Entrepreneurial Intention." Supervisor: Professor Zhou Xiaohu, School of Economics and Management, Nanjing University of Science and Technology, Nanjing, Jiangsu, China. For more information about this dissertation, you can contact [Mohammad_Heydari@njust.edu.cn] and [njustzxh@njust.edu.cn]. There are some questions contained in this paper, which symbolize the purpose of further research. Also, it is necessary to mention that this paper is the result of the ten years of research in different countries on "Human and Organizational Behavior".

2. The target population for this study was comprised of 400 students in Polish society who had graduated from programs of higher education from "Adam Mickiewicz University, Gdansk University of Technology, Jagiellonian University, Kozminski University, University of Lodz, University of Social Sciences and Humanities, University of Warsaw, University of Wroclaw." covering eight difference Polish universities and entrepreneurs consisting of entrepreneurs who had graduated from programs of higher education and other entrepreneurs who had not received any training in ethics.

\section{References}

Abelson, R. P., Kinder, D. R., Peters, M. D., \& Fiske, S. T. (1982). Affective and semantic components in political person perception. Journal of personality and social psychology, 42(4), 619. Abelson, R. P., Kinder, D. R., Peters, M. D., \& Fiske, S. T. (1982). Affective and semantic components in political person perception. Journal of personality and social psychology, 42(4), 619.

Ajzen, H., \& Fishbein, M. (1980). Understanding attitudes and predicting social behavior. 
Ajzen, I. (1974). Effects of information on interpersonal attraction: Similarity versus affective value. Journal of Personality and Social Psychology, 29(3), 374.

Ajzen, I. (1985). From intentions to actions: A theory of planned behaviour. Action Control: From Cognition to Behavior, 11-39.

Ajzen, I. (1987). Attitudes, traits, and actions: Dispositional prediction of behavior in personality and social psychology. In Advances in experimental social psychology (Vol. 20, pp. 163). Academic Press.

Ajzen, I. (1991). The theory of planned behavior. Organizational behavior and human decision processes, 50(2), 179-211.

Ajzen, I. (2005). Attitudes, personality, and behavior. McGraw-Hill Education (UK).

Ajzen, I., \& Driver, B. L. (1991). Prediction of leisure participation from behavioral, normative, and control beliefs: An application of the theory of planned behavior. Leisure sciences, 13(3), 185-204.

Ajzen, I., \& Driver, B. L. (1992). Application of the theory of planned behavior to leisure choice. Journal of leisure research, 24(3), 207-224.

Ajzen, I., \& Fishbein, M. (1977). Attitude-behavior relations: A theoretical analysis and review of empirical research. Psychological bulletin, 84(5), 888.

Ajzen, I., \& Madden, T. J. (1986). Prediction of goal-directed behavior: Attitudes, intentions, and perceived behavioral control. Journal of experimental social psychology, 22(5), 453-474.

Ajzen, I., \& Timko, C. (1986). Correspondence between health attitudes and behavior. Basic and applied social psychology, 7(4), 259-276.

Ali, F., Rasoolimanesh, S. M., Sarstedt, M., Ringle, C. M., \& Ryu, K. (2018). An assessment of the use of partial least squares structural equation modeling (PLS-SEM) in hospitality research. International Journal of Contemporary Hospitality Management.

Anderson, N. H. (1974). Cognitive algebra: Integration theory applied to social attribution. In Advances in experimental social psychology (Vol. 7, pp. 1-101). Academic Press.

Atkinson, J. W. (1964). An introduction to motivation.

Bagozzi, R. P. (1981). Attitudes, intentions, and behavior: A test of some key hypotheses. Journal of personality and social psychology, 41(4), 607.

Bagozzi, R. P. (1986). Attitude formation under the theory of reasoned action and a purposeful behaviour reformulation. British Journal of Social Psychology, 25(2), 95-107.

Bagozzi, R. P. (1989). An investigation of the role of affective and moral evaluations in the purposeful behaviour model of attitude. British Journal of Social Psychology, 28(2), 97113.

Bagozzi, R. P., \& Warshaw, P. R. (1990). Trying to consume. Journal of consumer research, 17(2), 127-140.

Bagozzi, R. P., \& Warshaw, R. R. (1990). An examination of the etiology of the attitude-behavior relation for goal-directed and mindless behaviors. Multivariate Behavioral Research.

Bagozzi, R. P., Baumgartner, J., \& Yi, Y. (1989). An investigation into the role of intentions as mediators of the attitude-behavior relationship. Journal of Economic psychology, 10(1), 35-62.

Bandura, A. (1977). Self-efficacy: toward a unifying theory of behavioral change. Psychological review, 84(2), 191.

Bandura, A. (1982). Self-efficacy mechanism in human agency. American psychologist, 37(2), 122.

Bandura, A. (1986). Social foundations of thought and action. Englewood Cliffs, NJ, 1986.

Bandura, A. (1991). Social cognitive theory of self-regulation. Organizational behavior and human decision processes, 50(2), 248-287.

Bandura, A. (2010). Self-efficacy the corsini encyclopedia of psychology. John Wiley \& Sons, Inc. doi, 10(9780470479216), 1-3.

Bandura, A., \& Walters, R. H. (1977). Social learning theory (Vol. 1). Englewood Cliffs, NJ: Prentice-hall. 
Bandura, A., Adams, N. E., \& Beyer, J. (1977). Cognitive processes mediating behavioral change. Journal of personality and social psychology, 35(3), 125.

Bandura, A., Adams, N. E., Hardy, A. B., \& Howells, G. N. (1980). Tests of the generality of self-efficacy theory. Cognitive therapy and research, 4(1), 39-66.

Beck, L., \& Ajzen, I. (1991). Predicting dishonest actions using the theory of planned behavior. Journal of research in personality, 25(3), 285-301.

Bentler, P. M., \& Speckart, G. (1979). Models of attitude-behavior relations. Psychological review, $86(5), 452$.

Breckler, S. J., \& Wiggins, E. C. (1989). On defining attitude and attitude theory: Once more with feeling. Attitude structure and function, 407-427.

Budd, R. J. (1987). Response bias and the theory of reasoned action. Social Cognition, 5(2), 95107.

Campbell, D. T. (1963). Social attitudes and other acquired behavioral dispositions.

Canary, D. J., \& Seibold, D. R. (1984). Attitudes and behavior: An annotated bibliography. Greenwood.

Dawes, R. M. (1972). Fundamentals of attitude measurement.

Di Paola, N., Spanò, R., Vona, R., \& Caldarelli, A. (2016). Why do life scientists decide to become entrepreneurs? The role of motivations. International Journal of Business and Management, 11(5), 57-68.

Dillon, W. R., \& Kumar, A. (1985). Attitude organization and the attitude-behavior relation: A critique of Bagozzi and Burnkrant's reanalysis of Fishbein and Ajzen.

Ellen, P. S., \& Madden, T. J. (1990). The impact of response format on relations among intentions, attitudes, and social norms. Marketing Letters, 1(2), 161-170.

Epstein, S. (1983). Aggregation and beyond: Some basic issues on the prediction of behavior. Journal of Personality, 51(3), 360-392.

Fishbein, M. (2008). An investigation of the relationships between beliefs about an object and the attitude toward that object.

Fishbein, M., \& Ajzen, I. (1974). Attitudes towards objects as predictors of single and multiple behavioral criteria. Psychological review, 81(1), 59.

Fishbein, M., \& Ajzen, I. (1977). Belief, attitude, intention, and behavior: An introduction to theory and research.

Fishbein, M., \& Ajzen, I. (1981). Attitudes and voting behavior: An application of the theory of reasoned action. Progress in applied social psychology, 1(1), 253-313.

Fredricks, A. J., \& Dossett, D. L. (1983). Attitude-behavior relations: A comparison of the Fishbein-Ajzen and the Bentler-Speckart models. Journal of personality and social psychology, 45(3), 501.

Ganic, E., Babic-Hodovic, V., \& Arslanagic-Kalajdzic, M. (2018). We are Happy Here and We Will Stay, What about You? The Cross-Level Impact of Employee Loyalty and Performance on Student Loyalty. South East European Journal of Economics and Business, 13(2), 7-18.

Godin, G., \& Shephard, R. J. (1987). Psychosocial factors influencing intentions to exercise in a group of individuals ranging from 45 to 74 years of age. $M$.

Gorsuch, R. L., \& Ortberg, J. (1983). Moral obligation and attitudes: Their relation to behavioral intentions. Journal of Personality and Social Psychology, 44(5), 1025.

Hart, D. W., \& Thompson, J. A. (2007). Untangling employee loyalty: A psychological contract perspective. Business Ethics Quarterly, 17(2), 297-323.

Heider, F. (1944). Social perception and phenomenal causality. Psychological review, 51(6), 358.

Holbrook, M. B. (1977). Comparing multiattribute attitude models by optimal scaling. Journal of Consumer Research, 4(3), 165-171.

Hull, C. L. (1943). Principles of behavior (Vol. 422). New York: Appleton-century-crofts.

Insko, C. A., Blake, R. R., Cialdini, R. B., \& Mulaik, S. A. (1970). Attitude toward birth control and cognitive consistency: theoretical and practical implications of survey data. Journal of Personality and Social Psychology, 16(2), 228.

Jaccard, J. J., \& Davidson, A. R. (1972). Toward an Understanding of Family Planning Behaviors: An Initial Investigation 1. Journal of Applied Social Psychology, 2(3), 228-235. 
Kuhl, J. (1984). Volitional aspects of achievement motivation and learned helplessness: Toward a comprehensive theory of action control. In Progress in experimental personality research (Vol. 13, pp. 99-171). Elsevier.

Lefcourt, H. M. (1981). Differentiating among internality, powerful others, and chance. Research with the locus of control construct, 1, 15-59.

Lefcourt, H. M. (1982). Locus of control: Current trends in theory and research (2e éd.). Hillsdale, É. U.: Erlbaum.

Lewin, K., Dembo, T., Festinger, L., \& Sears, P. S. (1944). Level of aspiration.

Liska, A. E. (1984). A critical examination of the causal structure of the Fishbein/Ajzen attitudebehavior model. Social psychology quarterly, 61-74.

Locke, E. A. (1965). Interaction of ability and motivation in performance. Perceptual and Motor Skills, 21(3), 719-725.

Locke, E. A., Mento, A. J., \& Katcher, B. L. (1978). THE INTERACTION OF ABILITY AND MOTIVATION IN PERFORMANCE: AN EXPLORATION OF THE MEANING OF MODERATORS 1. Personnel Psychology, 31(2), 269-280.

Manstead, A. S., Proffitt, C., \& Smart, J. L. (1983). Predicting and understanding mothers' infantfeeding intentions and behavior: testing the theory of reasoned action. Journal of personality and social psychology, 44(4), 657.

McGuire, W. J. (1985). Attitudes and attitude change. The handbook of social psychology, 233346.

Meyer, J. P., Becker, T. E., \& Vandenberghe, C. (2004). Employee commitment and motivation: a conceptual analysis and integrative model. Journal of applied psychology, 89(6), 991.

Miller, G. A. (1956). The magical number seven, plus or minus two: Some limits on our capacity for processing information. Psychological review, 63(2), 81.

Miniard, P. W., \& Cohen, J. B. (1981). An examination of the Fishbein-Ajzen behavioralintentions model's concepts and measures. Journal of Experimental Social Psychology, 17(3), 309-339.

Mischel, W. (1968). Consistency and specificity in behavior. Personality and assessment, 13-19.

Montano, D. E., \& Kasprzyk, D. (2015). Theory of reasoned action, theory of planned behavior, and the integrated behavioral model. Health behavior: Theory, research and practice, 70(4), 231.

Netemeyer, R. G., Burton, S., \& Johnston, M. (1991). A comparison of two models for the prediction of volitional and goal-directed behaviors: A confirmatory analysis approach. Social psychology quarterly, 87-100.

Orth, B. (1985). Bedeutsamkeitsanalysen bilinearer Einstellungsmodelle. Zeitschrift für Sozialpsychologie.

Otis, J., Godin, G., \& Lambert, J. (1990). AIDS prevention: Intentions of high school students to use condoms. Advances in Health Education, 4.

Petty, R. E., \& Cacioppo, J. T. (1986). The elaboration likelihood model of persuasion. In Communication and persuasion (pp. 1-24). Springer, New York, NY.

Pomazal, R. J., \& Jaccard, J. J. (1976). An informational approach to altruistic behavior. Journal of personality and social psychology, 33(3), 317.

Pratkanis, A. R. (1989). The Cognitive Representation. Attitude structure and function, 3, 71.

Rosenberg, M. J. (1956). Cognitive structure and attitudinal affect. The Journal of abnormal and social psychology, 53(3), 367.

Rotter, J. B. (1954). Social learning and clinical psychology.

Rotter, J. B. (1966). Generalized expectancies for internal versus external control of reinforcement. Psychological monographs: General and applied, 80(1), 1.

Sarver, V. T. (1983). Ajzen and Fishbein's" theory of reasoned action": A critical assessment.

Schifter, D. E., \& Ajzen, I. (1985). Intention, perceived control, and weight loss: an application of the theory of planned behavior. Journal of personality and social psychology, 49(3), 843. 
Schlegel, R. P., DAvernas, J. R., Zanna, M. P., DeCourville, N. H., \& Manske, S. R. (1992). Problem drinking: A problem for the Theory of Reasoned Action? 1. Journal of applied social psychology, 22(5), 358-385.

Schmidt, F. L. (1973). Implications of a measurement problem for expectancy theory research. Organizational Behavior and Human Performance, 10(2), 243-251.

Schwartz, S. H., \& Tessler, R. C. (1972). A test of a model for reducing measured attitudebehavior discrepancies. Journal of Personality and Social Psychology, 24(2), 225.

Shapero, A., \& Sokol, L. (1982). The social dimensions of entrepreneurship. Encyclopedia of entrepreneurship, 72-90.

Sheppard, B. H., Hartwick, J., \& Warshaw, P. R. (1988). The theory of reasoned action: A metaanalysis of past research with recommendations for modifications and future research. Journal of consumer research, 15(3), 325-343.

Sherman, S. J., \& Fazio, R. H. (1983). Parallals between attitudes and traits as predictors of behavior. Journal of personality, 51(3), 308-345.

Shook, C. L., \& Bratianu, C. (2010). Entrepreneurial intent in a transitional economy: an application of the theory of planned behavior to Romanian students. International Entrepreneurship and Management Journal, 6(3), 231-247.

Triandis, H. C. (1977). Interpersonal behavior. Brooks/Cole Pub. Co..

Valiquette, C. A., Valois, P., Desharnais, R., \& Godin, G. (1988). An item-analytic investigation of the Fishbein and Ajzen multiplicative scale: The problem of a simultaneous negative evaluation of belief and outcome. Psychological reports, 63(3), 723-728.

Van den Putte, B., \& Hoogstraten, J. (1990). The effect of variable order in measuring the theory of reasoned action. Unpublished manuscript, University of Amsterdam, Holland.

Van Ryn, M. (1991). The role of experimentally manipulated self-efficacy in determining job search behavior among the unemployed.

Vroom, V. (1964). Motivation and work.

Wallston, K. A., \& Wallston, B. S. (1981). Health locus of control scales. Research with the locus of control construct, 1, 189-243.

Wan, H. L. (2012). Employee loyalty at the workplace: The impact of Japanese style of human resource management. International Journal of Applied HRM, 3(1), 1-17.

Warehime, R. G. (1972). Generalized expectancy for locus of control and academic performance. Psychological Reports.

Wicker, A. W. (1969). Attitudes versus actions: The relationship of verbal and overt behavioral responses to attitude objects. Journal of Social issues, 25(4), 41-78.

Zhao, H., Seibert, S. E., \& Hills, G. E. (2005). The mediating role of self-efficacy in the development of entrepreneurial intentions. Journal of applied psychology, 90(6), 1265. 